\title{
Evaluation of mobile microwave electric field severity at Al-door residential complex in Iraq
}

\author{
Younes S. Alwan ${ }^{1}$, Mohammad Sami Zidan², Mohammed Qasim Taha ${ }^{3}$ \\ ${ }^{1}$ College of Engineering, University of Samarra /Samarra, Iraq \\ ${ }^{2}$ Technical Institute - Anbar, Middle Technical University (MTU), Iraq \\ ${ }^{3}$ Department of Biophysics, College of Applied Sciences-Heet, University Of Anbar, Iraq
}

\begin{tabular}{l} 
Article Info \\
\hline Article history: \\
Received Nov 11, \\
Revised Jan 13, 2019 \\
Accepted Feb 27, \\
\hline Keywords: \\
Electric field \\
Electromagnetics \\
Magnetic field \\
Radiations \\
SAR
\end{tabular}

Article Info

history:

\begin{abstract}
In this paper, the electromagnetic radiation of the mobile microwave signals, propagated by the mobile towers in Al-Door Residential Complex west of Iraq, is measured and evaluated. This complex contains main nodes and hub repeaters and feeders to transmit the service to the whole Salahuddin and the northern provinces. Therefore, this paper focused on this area to assess the radiation and to assess the radiation whether it is safe for humans or exceeded the dangerous level. The area has been divided on to 19 locations where there are mobile towers and the radiation is measured in these locations. The electric field intensity is unsafe and should be improved since it exceeds the level of $1.7 \mathrm{~V} / \mathrm{m}$. However, the magnetic field intensity is acceptable according to the measurements. In general, the electromagnetic radiation density is unsafe since many readings override the level of 1.3 $\mu \mathrm{W} / \mathrm{cm} 2$. The standards of the radiation severity are based on the recommendations of LATNEX Corp.
\end{abstract}

Copyright $(0) 2019$ Institute of Advanced Engineering and Science. All rights reserved.

\section{Corresponding Author:}

Mohammed Qasim Taha,

College of Applied Sciences-Heet,

University Of Anbar, Iraq.

Email: as.mohammad_taha@uoanbar.edu.iq

\section{INTRODUCTION}

The structure of the natural electromagnetic surrounding is produced from the terrestrial or the inside and the outside foundations such as electric charges that discharge within the surrounding of the earth and radiation from the outer space [1]. The fundamental of natural radiation is a very wide spectrum of frequencies where a high rate of transients and/or strong sharped-edged voltages that explode under various circumstances. What is called the natural background is the structure of magnitude or power below the levels produced by human-made radio frequency (RF) sources. The continuous use of machines, devices, and systems that emit radio frequency (RF) electromagnetic fields of radiations is rapidly growing. Foundations or sources that generate high levels of electromagnetic radiations are normally found in military and medical appliances and at specific places and labs. For Medical devices, there are many applications regarding magnetic resonance imaging (MRI), diathermic, hyper-thermic, multiple types of RF excision, surgical treatment, and diagnoses can lead to extreme levels of electromagnetic radiations at the ill's position or nearby inside the patient's organs. Furthermore, some of these medical appliances may produce high radiations at specific spaces [2].

The increasing power of RF radiation is commonly essential to have a greater zone of exposure to radiation. Electric field amplitudes can get to the level of kilo volts/meter $\mathrm{W} / \mathrm{m}$. Extreme values are also found near to multiple foundations utilized for the manufacturing of many tools by supplying heat and by the creation of plasmatic discharge in materials. In such usage of industry, radio frequency medical and safety complications get higher because radio frequency or (RF) power is great in value and might be problematic 
to surround the field-generating conductors with a powerful electromagnetic atmosphere. Foundations utilized by the common public, like wireless communicating systems, data broadcast, or material processing, produce in comparison greatly lower radiations at the location of the consumer [3].

In modern days, internet broadcasting, TV broadcasting, cellular networks of communications, etc. might cause significant levels of electromagnetic radiations in public areas. Multiple appliances related to cell phones, anyway, may cause apparently extreme peak levels of exposure while in use [4].

Many studies have been done showing the effect of electromagnetic radiations on: rat skin [5], sensitivity of plants, drug stability, DNA properties, ear canal hair follicle cells, human sperm motility, human brain, childhood development, biological system, and human health [6].

Despite all the concerns revealed by the specialists regarding the medical issues, it is still under investigation to show whether a specific radiation frequency causes an illness or medical obstacles. It is important and even critical to revealing the boundary conditions of any prospective harming radiationrelated applications or appliances. Therefore, the related authorities would be able to have a full comprehension for the up-to-date developments [7].

\section{METHODOLOGY}

The way that the study depended on is by picking an arbitrarily chosen city in Iraq. The city is Aldoor Complex, which has been built utilizing the technology of pre-casting with, somehow, dense population (15000 residents), and a small area (nearly $2 \mathrm{~km}^{2}$ ) as shown in Figure 1. It lies in the central part of Iraq in the Province of Saladin. This city is considered to have an organized population distribution that we can have enough comprehension of how the electromagnetic radiation behave in an urban area where people have a daily basis interaction with wide spectrum radiation [8].

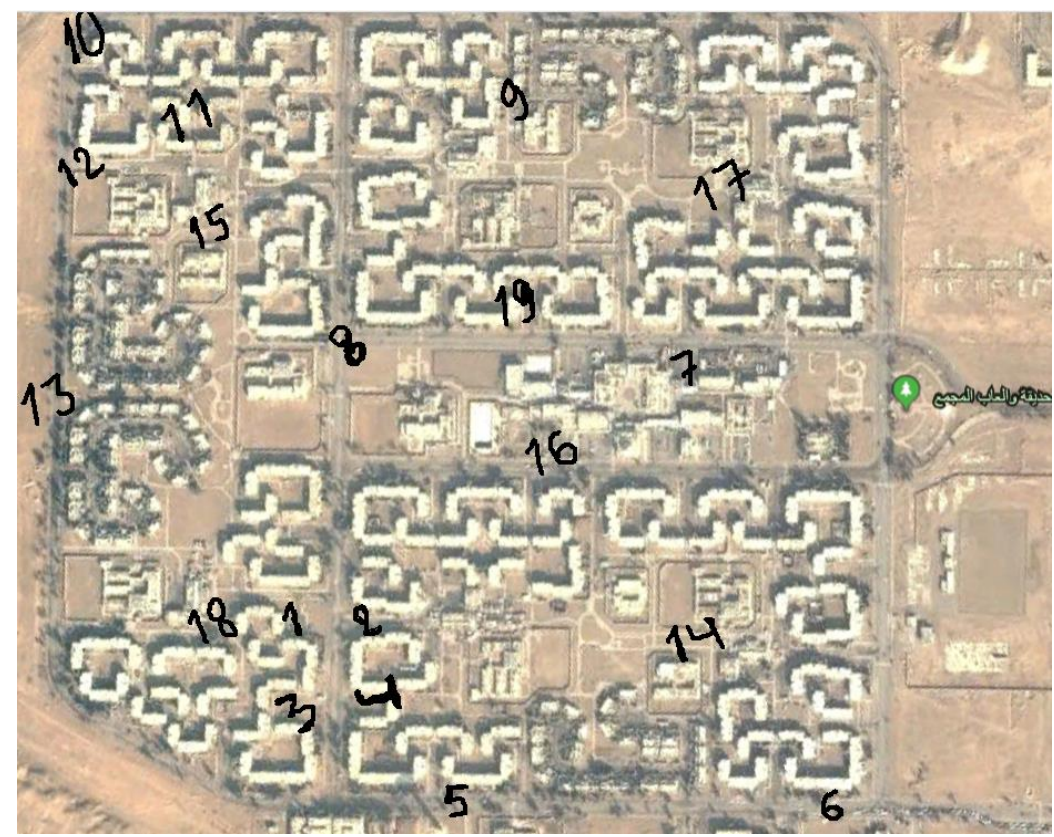

Figure 1. Top view of the Al-door residential complex

The bandwidth, which the study stood on, takes the range $50 \mathrm{MHz}$ up to $\approx 8 \mathrm{GHz}$ (the same range of the meter used). Thus, the prospective sources of electromagnetic radiations are the cellular networks, internet broadcastings, Wi-Fi appliances, WLAN, etc. It is worth mentioning that the bandwidths of these applications cover most of the radiation environment that common people interact with [9].

The setup of the study was done based on taking arbitrarily chosen and, somehow, normally distributed points. These points are within the densest areas in the chosen city. The electromagnetic parameter numbers were taken in a state of real time. i.e. A measurement meter was used to take values of magnetic field, electric field, radiation density, and SAR [10]. The mode used to take the values is the average value because the real-time display has a rapidly changing and cannot be taken as a reference for the 
study. The time, in which the parameters were taken, was chosen to be after the sunset due to some reasons. Some of which is that the sun during daylight emits a wide spectrum of frequencies that might contribute to the accuracy of the measurements [12]. There are standards of electromagnetic radiations upon which the measurements should not exceed in any urban or residential area. Such standards have been taken in accordance with many medical, environmental, and technical considerations along with survey reports. As indicated earlier in this paper, there are dangers of having medical problems regarding radiation absorption by the living tissues and adversely affecting them [12].

Another set of measurements was taken inside apartments and indoor areas hence people mostly live in closed shelters. There are dangers of radiations inside houses and apartments because of the outside penetrating radiations or the inside routers and broadcasting tools [13].

\subsection{Measurement Tool}

The tool used for taking measurements is called Triple Axis RF/High-Frequency Meter HF-B3G manufactured by LANTEX Corporation. The meter can measure from $50 \mathrm{MHz}$ up to $\approx 8 \mathrm{GHz}$. The device is shown in Figure 2.

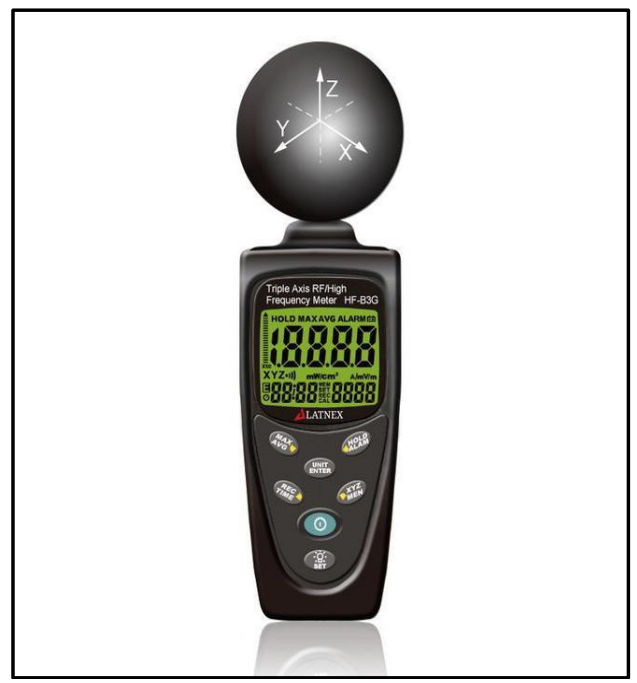

Figure 2. Triple axis RF/High-frequency meter HF-B3G

\subsection{Safety Recommendations}

Many specialized institutions have indicated levels of allowed numbers of radiations that should not exceed their allocated numbers.

a) Electric field measurement: It is believed that $40 \mathrm{mV} / \mathrm{m}$ and below is believed to be safe. The readings between 40 and $100 \mathrm{mV} / \mathrm{m}$ are considered to be concern that should have some steps to be taken in order to reduce these levels. If the readings are greater than $100 \mathrm{mV} / \mathrm{m}$, the environment is unsafe, and the health is under danger.

b) Radiation density: according to some specialists, the reading should not exceed $0.003 \mu \mathrm{W} / \mathrm{cm}^{2}$. As the numbers increase, it means that the environment exposes to high levels of EMF.

c) Magnetic field exposure: It is recommended that the body should not expose to more than $2000 \mathrm{mG}$ (= $159540 \mathrm{~mA} / \mathrm{m}$ ) to keep safe according to ICNIRP and/or IEEE although a committee in McGill University suggests that negative biological reactions occur at levels below $1 \mathrm{mG}(=79.77 \mathrm{~mA} / \mathrm{m})$.

Specific Absorption Rate (SAR): The accepted levels of SAR differ from one country to another; In USA, obligations require the value with 1.6 watts/ kilograms or below. Whereas Europe requires 2 watts/ kilograms. In Iraq, there is no specific value of SAR. Therefore, we will consider 1.6 watts/ kilograms as a reference [14], [15]

\section{FINDINGS AND EVALUATION}

The results took place in Al-door Residential complex in arbitrarily, somehow, uniformly distributed chosen points as indicated earlier. Table 1 shows the findings of the electric field distribution. 
Table 1. Electric Field Distribution

\begin{tabular}{cccc}
\hline $\begin{array}{c}\text { Location } \\
\text { No. }\end{array}$ & $\begin{array}{c}\text { Electric field } \\
(\mathrm{mV} / \mathrm{m})\end{array}$ & $\begin{array}{c}\text { Magnetic } \\
\text { field }(\mathrm{mA} / \mathrm{m})\end{array}$ & $\begin{array}{c}\text { Radiation density } \\
\left(\mu \mathrm{W} / \mathrm{cm}^{2}\right)\end{array}$ \\
\hline 1 & 1720 & 4.5 & 0.15 \\
2 & 650 & 4 & 0.2 \\
3 & 1700 & 1.5 & 0.05 \\
4 & 860 & 3.5 & 0.15 \\
5 & 700 & 2.3 & 0.12 \\
6 & 960 & 1 & 0.04 \\
7 & 700 & 1.5 & 0.06 \\
8 & 580 & 2 & 0.07 \\
9 & 1100 & 1.3 & 0.045 \\
10 & 500 & 2.2 & 0.2 \\
11 & 60 & 1.3 & 0.12 \\
12 & 58 & 0.1 & 0.001 \\
13 & 65 & 0.22 & 0.002 \\
14 & 220 & 0.16 & 0.001 \\
15 & 57 & 0.6 & 0.01 \\
16 & 600 & 0.13 & 0.001 \\
17 & 40 & 1.4 & 0.08 \\
18 & 500 & 0.1 & 0.0001 \\
19 & 1600 & 1.7 & 0.1 \\
\hline
\end{tabular}

In Table 1, the values in general are extremely higher than the recommended value. It means that the whole environment is polluted by the EMF radiation. The table also shows the distribution of the magnetic field in the allocated area. Also, the magnetic field radiation is within the recommended level of safety. Radiation density distribution is measured in $\mu \mathrm{W} / \mathrm{cm}^{2}$ units. Most of the readings of the radiation density are out of safety range and urgent actions must be taken to make these risky values within the safe range. There are locations $(12,13,14,16$, and 18) with very low radiation measurements due to lack of communication towers and less residents as well. The specific absorption rate (SAR) can be found using (1) and its derivations.

$$
S A R=\frac{1}{V} \int_{\text {sample }} \frac{\sigma(r)|E(r)|^{2}}{\rho(r)} d r
$$

Where: $\sigma(r)$ is the conductivity of the material $\mathrm{S} / \mathrm{m}$

$E(r)$ is the electric field component in $\mathrm{V} / \mathrm{m}$

$\rho(r)$ is the mass density in $\mathrm{kg} / \mathrm{m}^{3}$

SAR value of the chosen points cannot exceed the value of $1.6 \mathrm{Watt} / \mathrm{kg}$ hence our maximum recorded value of radiation density is about $0.9 \mu \mathrm{W} / \mathrm{cm}^{2}$, and the recommended maximum value is about $400 \mu \mathrm{W} / \mathrm{cm}^{2}$ according to Frey report. Although LATEX Corp. recommends that it should not override $0.003 \mu \mathrm{W} / \mathrm{cm}^{2}$.

\section{CONCLUSION}

In This work, the electric field, magnetic field, radiation density, and SAR. Measurements in Al-Door Residential Complex are used to assess the electromagnetic radiation distribution. The observations show that the electric field is far away from safety and needs to be reevaluated by the provider mobile companies. Although magnetic field measurement is somehow high, it is still within the acceptable range according to global standards. The radiation density is controversial, LATNEX recommends the value must not exceed $0.003 \mu \mathrm{W} / \mathrm{cm}^{2}$. Therefore, the values observed are high and need to be changed. However, based on some reports, the radiation density is safe until the value reaches $400 \mu \mathrm{W} / \mathrm{cm}^{2}$ and SAR is safe accordingly. There are locations $(12,13,14,16$, and 18) with very low radiation since they are terminal locations and the area have less internet and communication towers and less residents as well.

\section{REFERENCES}

[1] Paolo Vecchia, Rüdiger Matthes, Gunde Ziegelberger James Lin, Richard Saunders, and Anthony Swerdlow, "Exposure to high-frequency electromagnetic fields, biological effects and health consequences (100 kHz-300 GHz)." Report, ICNIRP, 16/2009.

[2] Ali A. Salem, R. Abd-Rahman, M. S. Kamarudin, H. Ahmed, N.A. M. Jamail, N. A. Othman, M.F. M. Yousof, M. T. Ishak, S. Al-Ameri, "The effect of insulator geometrical profile on electric field distributions", Indonesian Journal of Electrical Engineering and Computer ScienceVol. 14, No. 2, May 2019, pp. 618-627 (2019). 
[3] Asheesh Gupta, Saurabh Verma, Kumar Vyonkesh Mani, Gaurav K. Keshri, Santanu Karmakar, Anju Yadav, and Manish Sharma, "Microwave frequency-Electromagnetic Field $10 \mathrm{GHz}$ Radiation Exposure Impact on Rat Skin: An Oxidative Stress Insight." 3rd International Conference on Microwave and Photonics (ICMAP 2018), 9-11 February, 2018.

[4] Ali Zamanian and Cy Hardiman, "Electromagnetic Radiation and Human Health: A Review of Sources and Effects.” High Frequency Electronics, p.p. 16-26, 2005.

[5] Alexander Nikitin, Diana Suhareva, Egor Mishchenko, Alesya Zubareva, Olga Shurankova, and Ruslan Spirov, "Influence of Electromagnetic Radiation of Extremely High Frequency on Sensitivity of Plants to Cold Stress." IEEE International Conference on Human System Interactions (HSI), pp. 607-610, 2016.

[6] Subramani Parasuraman and Krishnamoorthy Venkates Kumar, "Does Electromagnetic Radiation affect drug stability?.” Journal of Young Pharmacists, p.p. 1-2, 2018.

[7] Masroor Hassan Bukhari, Salma Batool, Yasir Raza, Omar Bagasra, Abbas Rizvi, Asifa Shah, Tashmeem Razzaki, and Tipu Sultan, "DNA electromagnetic properties and interactions-An investigation on intrinsic bioelectromagnetism within DNA.” Electromagnetic Biology and Medicine, p.p. 169-174, 2018.

[8] Mehmet Akdag, Suleyman Dasdag, Fazile Canturk, Mehmet Zulkuf Akdag, "Exposure to non-ionizing electromagnetic fields emitted from mobile phones induced DNA damage in human ear canal hair follicle cells." Electromagnetic Biology and Medicine, p.p. 66-75, 2018.

[9] Osman Erogul, Emin Oztas, Ibrahim Yildirim, Tayfun Kir, Emin Aydur, Gokhan Komesli, Hasan Cem Irkilata, Mehmet Kemal Irmak, and Ahmet Fuat Peker, "Effects of Electromagnetic Radiation from a Cellular Phone on Human Sperm Motility: An In Vitro Study.” Archives of Medical Research, p.p. 840-843, 2006.

[10] Mohammed Qasim Taha, Mustafa H. Al-Jumaili, Abdullah Khalid Ahmed, "Modeling the dielectric mediums impact on coaxial transmission line performance", Journal of Engineering and Applied Sciences, Volume 13 Issue 20, 2018.

[11] A. V. Kramarenko and U. Tan, "Effects of High-Frequency Electromagnetic Fields on Human EEG: A Brain Mapping Study.” Taylor \& Francis health sciences, p.p. 1007-1019, 2003.

[12] Cindy Sage and Ernesto Burgio, "Electromagnetic Fields, Pulsed Radiofrequency Radiation, and Epigenetics: How Wireless Technologies May Affect Childhood Development." The Society for Research in Child Development, Inc, p.p. 129-136, 2017.

[13] Mustafa Hamid Al-Jumaili, Ahmed Subhi Abdalkafor, Mohammed Qasim Taha, "Analysis of the Hard and Soft Shading Impact on Photovoltaic Module Performance Using Solar Module Tester” In Press, International Journal of Power Electronics and Drive Systems (IJPEDS).

[14] Siti Zura A. Jalil, Mohd N. Taib, Hasnain Abdullah Idris, and Megawati Mohd Yunus, "Examination of Human Body Frequency Radiation.” Proceedings of 2010 IEEE Student Conference on Research and Development (SCOReD 2010), Putrajaya, Malaysia, p.p. 4 - 7, 13 - 14 Dec. 2010.

[15] Siti Z. A. Jalil, Mohd Abdul Karim, Hasnain Abdullah, and Mohd Taib, "Instrument system setup for human radiation waves measurement." Proceedings of 2009 IEEE student conference on research and development, Malasia, p.p. $523-525,16-18$ Nov. 2009. 